\section{Military Technical College Kobry El-Kobbah, Cairo, Egypt.}

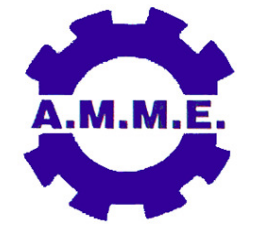

$17^{\text {th }}$ International Conference on Applied Mechanics and Mechanical Engineering.

\title{
EXPERIMENTAL AND NUMERICAL STUDIES ON EMULSION (OIL-IN-WATER) FLOW IN S-SHAPED DIFFUSERS
}

\author{
K. A. Ibrahim ${ }^{* * *}$, W. A. El-Askary ${ }^{* * *}$, I. M. Sakr ${ }^{* *}$ and H. A. Omara ${ }^{*}$
}

\begin{abstract}
Experimental and numerical studies on emulsion (oil-in-water) flow in rectangular cross-sectional area S-shaped diffusers have been carried out. The effects of different parameters including area ratio, curvature ratio, turning angle, flow path, inflow Reynolds number, oil concentration and emulsion status (stable/unstable) on the static pressure distributions and energy loss coefficient are considered. The numerical study is carried out using ANSYS R-15.0 software Fluid Flow Fluent (FFF) 3D with different turbulence models. The comparisons between the numerical results and experimental data show good agreement. The results indicate that the S-diffuser energy-loss coefficient is affected by the geometrical parameters of S-diffuser, and the flow parameters. The energy-loss coefficient for the case of stable emulsion is found to be greater than that of the unstable emulsion flow. A general correlation of energy-loss coefficient including geometrical and flow parameters for the validated studied cases of S-diffusers is developed in this paper.
\end{abstract}

\section{KEY WORDS}

Holdup;emulsion flow; turn angle; energy losses; S-shaped diffusers.

Assist. lecturer, Dept. of Mech. Power Eng., El-Arish Higher Institute of Eng., Ministry of Higher Education, Egypt.

** Lecturer, Dept. of Mech. Power Eng., Faculty of Engineering, Menoufia Univ. Shebin Elkom-Egypt.

*** Professor, Dept. of Mech. Power Eng., Faculty of Engineering, Menoufia Univ., Shebin El-Kom- Egypt. 


\section{NOMENCLATURE}

A Cross-sectional area, $m^{2}$

AR S-shaped area ratio $=A_{\text {exit }} / A_{\text {inlet }}$

B Height of the cross section diffuser, $m$

CC Concave wall

$\mathrm{C}_{d} \quad$ Discharge coefficient of the orifice flow meter

$\mathrm{C}_{\mathrm{P}} \quad$ Static pressure recovery coefficient $C_{p}=\left(P_{x}-P_{r e f}\right) /\left(0.5 \rho_{r e f} U_{r e f}^{2}\right)$

$\mathrm{CP}_{\mathrm{P}}(\mathrm{l}) \quad$ Ideal static pressure coefficient

$\mathrm{CP}_{\mathrm{Pi}} \quad$ Static pressure recovery coefficient on the inner wall

$\mathrm{CPo}_{\mathrm{P}} \quad$ Static pressure recovery coefficient on the outer wall

$\mathrm{CR} \quad \mathrm{S}$-diffuser curvature -ratio $=R_{c} / W$

CV Convex wall

$\mathrm{DH}_{\mathrm{H}} \quad$ Hydraulic diameter, $\mathrm{m}$

$\mathrm{K}_{\mathrm{d}} \quad$ Energy loss coefficient, $K_{d}=\left[\left(1-A R^{-2}\right)-\left(C_{P(\text { exit })}-C_{p(\text { inlet })}\right)\right]$

M Model number

$\mathrm{P} \quad$ Pressure, $\mathrm{Pa}$

Pexit $\quad$ S-shaped diffuser exit pressure, $\mathrm{Pa}$

Pinlet S-shaped diffuser inlet pressure, $\mathrm{Pa}$

Q Fluid flow rate, $\mathrm{m}^{3} / \mathrm{s}$

$\mathrm{R}_{\mathrm{c}} \quad$ Diffuser centre line arc radius, $m$

$\mathrm{Re}_{\mathrm{e}} \quad$ REYNOLDS number

$U_{\text {ref }} \quad$ Reference velocity is the mean streamwise velocity at the diffuser inlet, $\mathrm{m} / \mathrm{s}$

U Water axial velocity inside the diffuser parallel to the diffuser centreline, $\mathrm{m} / \mathrm{s}$

Uexit Exit flow velocity, $\mathrm{m} / \mathrm{s}$

Uinlet Inlet flow velocity, $\mathrm{U}_{\text {inlet }}=\mathrm{U}_{\text {ref }}, \mathrm{m} / \mathrm{s}$

$V_{E} \quad$ Emulsion volume, $\mathrm{m}^{3}$

Vo Oil volume, $\mathrm{m}^{3}$

$V_{w} \quad$ Water volume, $m^{3}$

W Inlet width, $\mathrm{m}$

$W_{\text {exit }} \quad$ Exit width, $m$

$\mathrm{X} \quad$ Distance along diffuser centreline, measured from the reference location, $\mathrm{m}$

\section{Greek Symbols}

$\Phi \quad$ Holdup (ratio of oil volume to emulsion volume)

$\mu \quad$ Dynamics viscosity, Pa.s

$\checkmark \quad$ Kinematics viscosity, $\mathrm{m}^{2} / \mathrm{s}$

$\mu_{w} \quad$ Water dynamic viscosity, Pa.s

$\mu_{m} \quad$ Emulsion dynamic viscosity, Pa.s

$\rho_{w} \quad$ Water density, $\mathrm{Kg} / \mathrm{m}^{3}$

$\rho_{o} \quad$ Oil density, $\mathrm{Kg} / \mathrm{m}^{3}$

$\rho_{m} \quad$ Emulsion density, $\mathrm{Kg} / \mathrm{m}^{3}$

$\theta_{1}^{o} / \theta_{2}^{o} \quad$ S-shaped diffuser first bend angle, second bend angle 


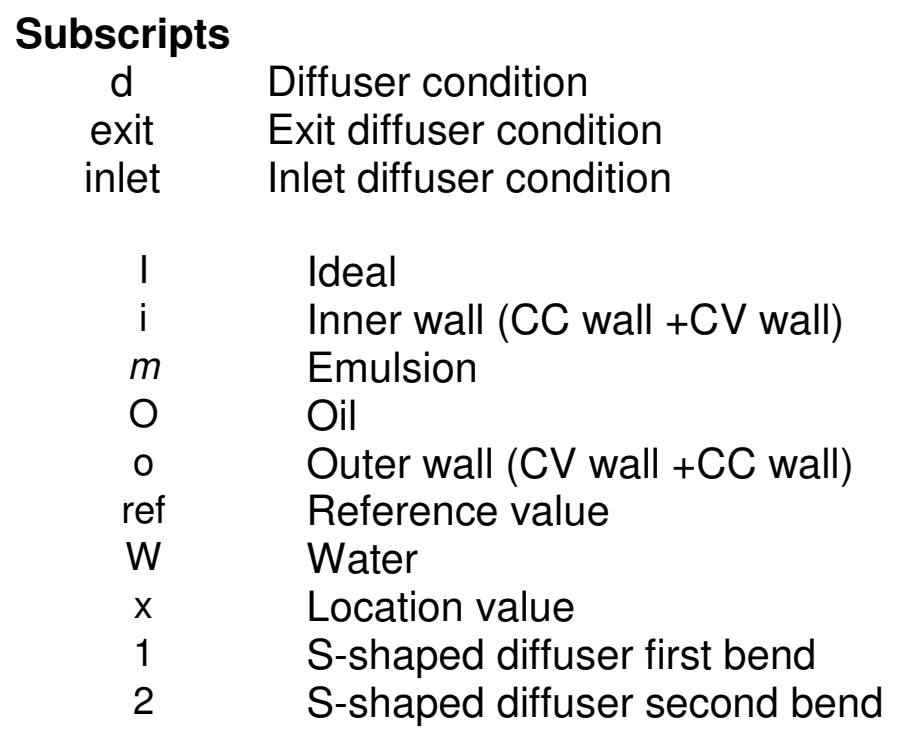

\title{
List of abbreviations
}

$\begin{array}{cl}\text { CFD } & \text { Computational Fluid Dynamics } \\ \text { EXP } & \text { Experimental data } \\ \text { FP } & \text { S-shaped diffuser flow path } \\ \text { (o/w) } & \text { (oil- in-water) emulsion } \\ \text { SDS } & \text { Sodium dodecyl sulphate } \\ \text { St. } & \text { Stable o/w emulsion } \\ \text { TA } & \text { S-shaped diffuser turn angle } \\ \text { Unst. } & \text { Unstable o/w emulsion } \\ \text { (w/o) } & \text { (water-in-oil) emulsion } \\ \text { WP } & \text { Wetted perimeter, m }\end{array}$

\author{
List of chemical symbol \\ $\mathrm{CCL}_{4} \quad$ Carbon Tetra Chloride \\ $\mathrm{CH}_{3}\left(\mathrm{CH}_{3}\right)_{11} \mathrm{OSO}_{3} \mathrm{Na} \quad$ Sodium Dodecyl Sulfate
}

\section{INTRODUCTION}

Emulsion is a mixture of two or more immiscible liquids, in which one or more phases are dispersed in the other continuous phase. The continuous phase is known as dispersion medium. Injection of water inside the crude oil in petroleum field to extract it easily is an important application for the emulsion flow. Emulsions are also used in many other industries, such as petroleum, pharmaceutical, agriculture and food industries. In many applications, pumping of emulsions through pipes and pipe fittings is required. Since a detailed physical description of the flow mechanism is still not possible for emulsion, a considerable effort is generally needed to calculate the pressure drop along the flow path. S-shaped diffusers are used in centrifugal pump used in oil extraction processes. Pressure gradients in S-diffusers resulting from streamline curvature, can produce significant secondary flows. Additionally, the adverse streamwise pressure gradient, caused by increasing cross-sectional area, can lead to flow separation. Flow separation in S-diffusers will cause flow distortion, which can result in high cycle fatigue, generated by unsteady dynamics loads. Regarding the costs, the ability to quickly predict complicated flow phenomena 
without experimental testing is obviously desirable for designers and therefore, different numerical studies were considered previously. The flow in S-shaped diffuser is complex because the flow is three dimensional and rotates and this causes the experimental and numerical studies difficult to be performed in such complex geometry. Generally, the literature was focused widely in single phase (air or water) developing flow in S-shaped diffusers considering different geometrical and flow parameters on the S-diffuser performance. However, emulsion flows were considered in some different simple geometries including sudden expansion or contraction based on experimental or numerical studies.

The problem of oil-in-water (o/w) emulsion flow through sudden expansion has been numerically investigated by Roul and Sahoo [1]. They found that; the expansion loss coefficient is independent of the Reynolds number and is not significantly influenced by the type and concentration of (o/w) emulsions. They indicated also that; the effect of viscosity is negligible on the pressure drop but the pressure drop increases with higher mass flow rate.

Emulsion (oil-in-water) fluid flow in curved diffusers was first experimentally conducted by El-Askary et al. [2]. They concluded that the outer wall pressure coefficient is higher than that the inner wall and the energy-loss coefficient, $\mathrm{Kd}$, is found to be inversely proportional to Reynolds number, diffuser area ratio and diffuser curvature ratio. Increasing emulsion holdup increases energy-loss coefficient. The hydraulic resistances of emulsion (oil- in-water) flow across orificemeter, venturi-meter, sudden contraction and sudden enlargement were measured by Nasr [3]. She showed that under the same flow Reynolds numbers; increasing the oil concentration causes enhancement of the energy losses. Under the same oil concentration; increasing flow Reynolds number causes a decreasing in energy-loss coefficient. The velocity and the pressure characteristics of the water flow in an Sshaped diffusing duct with asymmetric inlet conditions have been measured by Whitelaw and $\mathrm{Yu}$ [4] and simulated by Whitelaw and $\mathrm{Yu}$ [5]. The results showed that the Navier-Stokes equations are appropriate to predict the details of the near wall flows and the flow distorts the second half of the S-shaped diffuser. Turbulent flow characteristics in a round cross-sectional S-shaped diffusing duct were measured by Whitelaw and $\mathrm{Yu}$ [6]. They found that; the size of separation region increases with thinning the inlet boundary layer.

An experimental study concerning the laminar and turbulent pipe flow behaviors of unstable and stable (w/o) and (o/w) emulsions was performed by Pal [7]. He showed that; the unstable (o/w) emulsions exhibit drag reduction depending upon the holdup of the dispersed phase. The unstable (w/o) emulsions exhibit much stronger drag reduction than the unstable o/w emulsions. The stable emulsions exhibit relatively little drags reduction. Hwang and Pal [8] studied experimentally the flow of twophase (o/w) emulsions through sudden expansions and contractions. They found that; the loss coefficient for emulsions is independent of the concentration and type of emulsions. Pal and Hwang [9] studied experimentally the energy-loss coefficients for flow of stable (o/w) emulsions through different pipe components (valve, expansion and contraction). They showed that; emulsions can be treated as Newtonian only at low concentrations of dispersed phase. Also, the frictional losses could be successfully correlated as loss coefficient versus Reynolds number. The pressure drop of (o/w) emulsion flow through sudden contraction and expansion in a horizontal pipe was measured by Balakhrisna et al. [10]. They showed that the 
abrupt change in area during oil-water flow through pipe strongly affects the phase distribution. Experimental and numerical studies on water flow through rectangular cross-sectional area S-shaped diffusers were conducted by Ibrahim et al. [11]. The measurements showed that as the turn angle increases from $45^{\circ} / 45^{\circ}$ to $90^{\circ} / 90^{\circ}$, the energy-loss coefficient increases and as the flow path changes from $45^{\circ} / 45^{\circ}$ to $60^{\circ} / 30^{\circ}$, the energy-loss coefficient strongly increases. Ibrahim et al. [11] concluded that the S-shaped diffuser energy-loss coefficient is inversely proportional to the inflow Reynolds number, diffuser area ratio and diffuser curvature ratio.

The focused literature review showed the importance of studies performed on Sshaped and curved diffusers. In spite of such importance, the first type (S-shaped diffuser) has a narrow space of studies, either experimental or numerical for single phase flows. However, no studies have been performed on emulsion flow in Sdiffusers. The main objective of the present work is to gain an in-depth study of flow of $(\mathrm{o} / \mathrm{w})$ emulsion in a rectangular cross-sectional area S-shaped diffuser to understand its performance. In the present work the effects of the geometrical parameters of the S-shaped diffuser such as the area ratio, curvature ratio, turning angle and flow path are considered and the inflow parameters such as the inflow Reynolds number, the holdup and stability/instability of the emulsion are also included in order to extract general conclusions.

\section{EXPERIMENTAL SETUP AND PHYSICAL MODEL}

The experimental apparatus and the instruments required to perform the experimental measurements are illustrated in Fig. 1. It consists mainly of two parts, the oil-in-water emulsion circuit (a) and the test section model (b). The emulsion is prepared using tap water and a refined white mineral oil of density $840 \mathrm{Kg} / \mathrm{m}^{3}$, kinematic viscosity limits from 13 to 19 centi-Stoke $\left(10^{-6} \mathrm{~m}^{2} / \mathrm{s}\right)$. The experiments in first set for unstable emulsion begin with tap water into which a required amount of oil concentration varies from 0.0 to 0.25 of emulsion volume. In the second set of emulsion, an ionic surfactant namely Sodium Dodecyl Sulfate is adding to the oil with $1.5 \%$ based on the water weight to generate stable emulsion. The density and viscosity of water and oil-in water emulsion are measured using densitometer and viscometer as in Refs. [2] and [3]. The emulsion flow rate is measured by calibrated orifice meter and controlled by gate valve placed after the pump delivery. The setup is equipped with flow rate instrument (orifice flow meter) and walls static taps connected to multi-tubes manometer for the outer and inner walls static-pressure measurements. The measuring fluid used in the manometer is Carbon Tetra Chloride (CCL4) that has specific gravity of 1.4. The relation between emulsions flow discharge coefficients with different emulsion holdup in case of stable and unstable emulsion at different Reynolds numbers were registered in Ref. [2]. Percentage uncertainty of the energy-loss coefficients of S-shaped diffuser models with emulsion and water flows during all measurements were: $2.2 \leq \pm U_{k_{d}} \leq 4.5$ by the same method in Refs. [2, 3 and 12]. A schematic of the physical model is shown in Fig.1.b. The studied models consist of two bends at different degrees, curvature radius from 100 to $250 \mathrm{~mm}$ and different area ratios. Table 1 indicates the dimensions of all cases that used in the present studies. The physical domain of the S-shaped diffuser is composed of four sections as shown in Fig.1.b. The first section is an entrance flat straight rectangular section to diffuser inlet (upstream tangent duct), then two curved 
diverged side-wall sections (the two bends of S-diffuser), and flat straight rectangular section at diffuser outlet (downstream tangent duct) for flow recovery.

\section{MATHEMATICAL MODEL}

A first approximation to model emulsion flow behaviour is to consider it as two-phase Newtonian fluid. The first step in mathematical modeling is to decide which twophase flow model can be used. The choice of the model depends on the type of problem of interest. The present problem can be considered as a mixed flow case in a relatively short S-shaped diffuser. There are four main models currently used in two-phase flow; Euler model, mixture model, volume of fluid model and Lagrange model. Theoretically, the two-phase flow problem can be solved by any one of the four models. However, neither the Lagrange nor the volume of fluid models can be used due to the huge number of oil droplets which consumes extra -ordinary long computing time. Previous publications in literature have considered that the emulsion can be treated as a pseudo-homogeneous fluid with suitably averaged properties as the dispersed droplets of emulsion are small and well dispersed. Consequently the mixture model solves for the mixture momentum equations and prescribes relative velocities to describe the dispersed phases. The effects like aggregation, breakage and coalescence phenomena will not be analyzed in the present study. The mathematical model is based on solver proposed by [12]. In the present paper, CFD simulations are carried out using ANSYS R-15.0 with software Fluid Flow Fluent (FFF) which applies 3D-RANS (Reynolds Averaged Navier-Stokes equations) method.

\section{Continuity Equation for the Mixture}

$\nabla \cdot\left(\rho_{\mathrm{m}} \mathrm{v}_{\mathrm{m}}\right)=0$

where $\overrightarrow{\mathrm{V}}_{\mathrm{m}}$ is the mixture mass-averaged velocity [12]: $\overrightarrow{\mathrm{v}}_{\mathrm{m}}=\frac{\sum_{\mathrm{k}=1}^{\mathrm{n}} \alpha_{\mathrm{k}} \rho_{\mathrm{k}} \overrightarrow{\mathrm{V}}_{\mathrm{k}}}{\rho_{\mathrm{m}}}$ and $\rho_{\mathrm{m}}$ is the mixture density: $\rho_{\mathrm{m}}=\sum_{\mathrm{k}=1}^{\mathrm{n}} \alpha_{\mathrm{k}} \rho_{\mathrm{k}} \quad \alpha_{k}$ is the volume fraction of phase $k$.

\section{Momentum Equation for the Mixture}

$$
\nabla \cdot\left(\rho_{\mathrm{m}} \overrightarrow{\mathrm{V}}_{\mathrm{m}} \overrightarrow{\mathrm{V}}_{\mathrm{m}}\right)=-\nabla \mathrm{p}+\nabla \cdot\left[\mu_{\mathrm{m}}\left(\nabla \overrightarrow{\mathrm{V}}_{\mathrm{m}}+\nabla \overrightarrow{\mathrm{V}}_{\mathrm{m}}^{\mathrm{T}}\right)\right]+\rho_{\mathrm{m}} \overrightarrow{\mathrm{g}}+\overrightarrow{\mathrm{F}}+\nabla \cdot\left(\sum_{\mathrm{k}=1}^{\mathrm{n}} \alpha_{\mathrm{k}} \rho_{\mathrm{k}} \overrightarrow{\mathrm{V}}_{\mathrm{dr}, \mathrm{k}} \overrightarrow{\mathrm{V}}_{\mathrm{dr}, \mathrm{k}}\right)
$$

where $\mathrm{n}$ is the number of phases, $\vec{F}$ is a body force, and $\mu_{\mathrm{m}}$ is the viscosity of the mixture: 
$\mu_{\mathrm{m}}=\sum_{\mathrm{k}=1}^{\mathrm{n}} \alpha_{\mathrm{k}} \mu_{\mathrm{k}}$ and $\overrightarrow{\mathrm{v}}_{\mathrm{dr}, \mathrm{k}}$ is the drift velocity of secondary phase $k: \quad \overrightarrow{\mathrm{V}}_{\mathrm{dr}, \mathrm{k}}=\overrightarrow{\mathrm{V}}_{\mathrm{k}}-\overrightarrow{\mathrm{V}}_{\mathrm{m}}$

\section{Volume Fraction Equation of the Secondary Phase}

From the continuity equation of secondary phase $p$, the volume fraction can be obtained from:

$$
\nabla \cdot\left(\alpha_{\mathrm{p}} \rho_{\mathrm{p}} \overrightarrow{\mathrm{v}}_{\mathrm{m}}\right)=-\nabla \cdot\left(\alpha_{\mathrm{p}} \rho_{\mathrm{p}} \overrightarrow{\mathrm{v}}_{\mathrm{dr}, \mathrm{p}}\right)+\sum_{\mathrm{q}=1}^{\mathrm{n}}\left(\dot{\mathrm{m}}_{\mathrm{qp}}-\dot{\mathrm{m}}_{\mathrm{pq}}\right)
$$

\section{Turbulence Modeling}

The turbulence is simulated via choosing of different available turbulence models in FLUENT [12]. However, because of the successful results of the slandered $k-\varepsilon$ model, it will be here only widely discussed as it is the simplest turbulence model. Before its choosing, different tests on different turbulence models are performed and the results are compared with different measurements to verify the ability of the standard $k-\varepsilon$. The equations governing the turbulent kinetic energy $k$ and its dissipation rate $\varepsilon$ read:

$$
\begin{aligned}
& \nabla \cdot\left(\rho_{\mathrm{m}} \overrightarrow{\mathrm{V}}_{\mathrm{m}} \mathrm{k}\right)=\nabla \cdot\left[\left(\mu_{\mathrm{m}}+\frac{\mu_{\mathrm{t}, \mathrm{m}}}{\sigma_{\mathrm{k}}}\right) \nabla \mathrm{k}\right]+\mathrm{G}_{\mathrm{k}, \mathrm{m}}-\rho_{\mathrm{m}} \varepsilon \\
& \nabla \cdot\left(\rho_{\mathrm{m}} \overrightarrow{\mathrm{V}}_{\mathrm{m}} \varepsilon\right)=\nabla \cdot\left[\left(\mu_{\mathrm{m}}+\frac{\mu_{\mathrm{t}, \mathrm{m}}}{\sigma_{\varepsilon}}\right) \nabla \varepsilon\right]+\frac{\varepsilon}{\mathrm{k}}\left(\mathrm{C}_{1 \varepsilon} \mathrm{G}_{\mathrm{k}, \mathrm{m}}-\mathrm{C}_{2 \varepsilon} \rho_{\mathrm{m}} \varepsilon\right)
\end{aligned}
$$

where $G_{k, m}$ is the mixture turbulent kinetic production term.

The turbulent viscosity of the mixture is computed from $\mu_{\mathrm{t}, \mathrm{m}}=\rho_{\mathrm{m}} \mathrm{C}_{\mu} \frac{\mathrm{k}^{2}}{\varepsilon}$ and the model constants are; $\mathrm{C}_{\varepsilon 1}=1.44, \mathrm{C}_{\varepsilon 2}=1.2, \mathrm{C}_{\varepsilon 3}=1.2, \mathrm{C}_{\mu}=0.09, \sigma_{\mathrm{k}}=1$ and $\sigma_{\varepsilon}=1.3$.

\section{BOUNDARY CONDITIONS AND NUMERICAL SOLUTION PROCEDURE}

\section{Boundary Conditions}

It has long been recognized that diffuser performance depends not only on the physical shape of the duct but also upon the type of inflow conditions. For each case, structured grid is generated using ANSYS R15.0 meshing, which is utilized from the adaptive meshing capability of the used code. The present simulations are conducted at different Reynolds numbers ranging from 9000 to 34000 based on the S-diffuser inlet hydraulic diameter of $32 \mathrm{~mm}$. The inlet velocity boundary condition depends on the inflow Reynolds number. It is worth noting that at the maximum opening of the 
flow control valve that corresponding to $\mathrm{Re}=34000$ for the case of water, the value of maximum Reynolds cannot be reached for the cases of $\Phi \geq 0.1$, because of the increased viscosity of the mixture. The inflow mean velocity is computed based on Reynolds number and $1 / 7^{\text {th }}$ power-law velocity profile is implemented at the inlet. The pressure outlet boundary conditions are specified at the exit of the S-diffuser downstream tangent duct. For S-diffuser and its tangent ducts boundaries, the walls with no slip boundary conditions are used and the solution initialization is taken from inlet.

\section{Numerical Solution Procedure}

The objective of the present work is to simulate the o/w emulsion flow through an Sshaped diffuser by using two-phase flow mixture scheme. The flow field is assumed to be Cartesian and solved in three dimensions. The three-dimensional equations of mass, momentum and turbulent quantities along with the boundary conditions have been integrated over a control volume and the subsequent equations have been discretized over the control volume using a finite volume technique to yield algebraic equations which are solved using ANYSIS Fluent R15.0 CFD code. The discretization form for all the convective variables are taken to be first order unwinding initially for better convergence. The Phase-Coupled SIMPLE algorithm is used for the pressure-velocity coupling. The velocities are coupled by the phases, but in a segregated fashion. The mixture standard $k-\varepsilon$ model has been used as closure model for turbulent flow. Fine grids are used near the walls especially near the curved diverged walls to capture more details about velocity, turbulent stresses, and other flow behaviours. To obtain mesh-independent solution, the adaptive meshing method is applied and maximum number of cells for a volume of emulsion flow within S-shaped diffuser of Model 7 is 1080000 cells as shown in Fig. 2. The cross section contain $60 \times 60$ cells and the streamwise direction has 85 nodes in the upstream duct, 120 nodes in the diffuser, and 215 nodes in the downstream tangent. The resolution for simulation of Model 7 is chosen based on different tests for emulsion flow, in which the computations are carried out for different resolutions (cells of 500000, 1080000 and 1500000). The static pressure recovery coefficient is monitored for each grid with experimental measurements. The results indicate that the medium grid (1080000) can be used as it produces suitable data in view of the comparisons with the experimental results of the pressure coefficient, see Fig. 3. However, this is not the grid used in all simulations but the resolution depends on the studied case, but keeping in consideration for all cases the nearest wall non-dimensional distance $\Delta y^{+}=\Delta z^{+}=1.5$. The simulations are performed using three multiphase models namely, Volume of Fluid (VOF), Eulerian and Mixture models. The comparisons with the present measurements show that the pressure coefficient profile is successfully predicted using the Mixture model, see Fig. 4. Therefore, the Mixture model will be used as a solution multiphase model for simulating the $\mathrm{o} / \mathrm{w}$ emulsion flow. Further verification is performed via comparisons of the present simulation with the measurements of El. Askary et al. [2] for emulsion flow ( $\Phi=0.1$ stable) in curved diffuser, see Fig. 5. The last verification is considered for emulsion flow through sudden expansion pipe and hence complex phenomena including separation of emulsions flow with different hold-ups ( $\Phi=0.2144$ and $\Phi=0.6035$ unstable), see Hwang and Pal [8]. From the different verifications, the mixture model 
and slandered $k-\varepsilon$ model can be extended for predicting the performance of $\mathrm{S}$ diffuser carrying emulsion flow and will be discussed in the next section.

\section{RESULTS AND DISCUSSION}

The simulation and experiments are extended to different S-diffuser models, see Table 1. In the present study, it is aimed to extract the energy-loss coefficients (flow resistance coefficients) for the S-shaped curved diffusers with different area ratios: 1.5, 2, and 3, different curvature ratios: $C R=R_{c} / W=5,7.5$, and 12.5, different flow paths: $45^{\circ} / 45^{\circ}, 60^{\circ} / 30^{\circ}$ and $30^{\circ} / 60^{\circ}$, and different turn angles: $45^{\circ} / 45^{\circ}, 60^{\circ} / 60^{\circ}$ and $90^{\circ} / 90^{\circ}$. However, the geometrical parameters of all models of the S-shaped curved diffusers are given in Table 1. The results in the form of energy loss coefficients are presented experimentally and numerically for the unstable and stable (o/w) emulsions at different holdup $(\Phi)$ values from 0.03 to 0.25 . The results are presented at different diffuser inflow Reynolds numbers range of $9,000 \leq \operatorname{Re} \leq 34,000$, where $\operatorname{Re}=\frac{\rho_{m} U_{r e f} D_{H}}{\mu_{m}}$ with $D_{H}=\frac{2 W B}{W+B}$ (the hydraulic diameter).

The energy-loss coefficients is strongly affected by inflow Reynolds number, emulsion holdup, emulsion status, S-diffuser area ratio, curvature ratio, turn angle and S-diffuser flow path as the following experimental and numerical results show. All the following computations are performed using Mixture model as a suitable multiphase model and standard $k-\varepsilon$ turbulence model for simulations of emulsion flow based on validations with [2] and [8], see Figs. 5 and 6.

\section{Diffuser Performance}

The pressure recovery coefficients are first measured and computed from which the corresponding energy-loss coefficients are extracted for water as well as stable/unstable emulsions. The effect of diffuser inflow Reynolds number on the energy-loss coefficient for all S-diffuser tested models is shown in Fig. 7. The effect of emulsion holdup (ranged from 0.03 to 0.25 ) on the energy-loss coefficient for Sdiffuser tested models: 3, 5, 7, 11 is shown in Fig. 8. It is noticed that the energy-loss coefficient $\left(\mathrm{K}_{\mathrm{d}}\right)$ is directly proportional to the holdup $(\Phi)$ because of the increase of fluid viscosity with increasing $\Phi$. In all cases the less coefficient decreases with increasing Reynolds as previously concluded in El-Askary et al. [2].

The effect of emulsion stability/instability on the energy-loss coefficient of S-diffuser models: 2, 3, 7, 12 is presented in Fig. 9 and it is found that the energy-loss coefficient decreases in case of unstable emulsion because this emulsion lubricates the S-diffuser side walls and hence increasing the friction drag. The energy-loss coefficient of the S-shaped diffusers decreases as the area ratio or the curvature ratio increases as shown in Figs. 10 and 11, respectively. The effect of S-diffuser symmetric turn angle is shown in Fig. 12, and the loss coefficient is observed to increase with the turn angle (models 7, 8, and 9). The S-shaped diffuser energy-loss coefficient is strongly affected by diffuser flow path since it is noticed clearly that it decreases for symmetric turn angle and increases with asymmetric turn angle (models 10, 11, and 12) as shown in Fig. 13. The S-diffuser energy-loss coefficient 
approaches asymptotic values for high diffuser inflow Reynolds number. For the same radius of curvature, i.e. an equal main-flow pass, the pressure gain from the widest diffuser (the highest area ratio) is higher than the energy lost due to intensive secondary flows produced. It means that the diffuser energy loss decreases with increasing the area ratio, see Fig. 10. The main reason of the curvature ratio effects is the decreasing of the centrifugal force created in the S-shaped curved diffuser with increasing the curvature ratio, which is responsible for secondary flow generation. As the curvature ratio decreases the energy loss in the S-shaped diffuser increases, because of the generation of strong secondary flows (with small radius of curvature) superimposed on the mean flow, see Fig. 11. The diffuser energy-loss coefficient is also affected by the change of the symmetric turn angle because of the different three models turn angles are symmetric and as the turn angle increases, the energyloss coefficient increases, since the intensity of the generated vortices is being stronger for the higher angle of turn and this causes relatively high flow resistance through the S-diffuser, see Fig. 12. At the same Reynolds number, the same curvature radius and the same total turn angles of $90^{\circ}\left(45^{\circ} / 45^{\circ}, 30^{\circ} / 60^{\circ}\right.$ and $\left.60^{\circ} / 30^{\circ}\right)$ the energy-loss coefficient strongly increases, respectively. This behaviour depends on the created secondary flows because of the strong turn of the asymmetric bend of S-shaped diffuser. The presence of asymmetric turn angle increases the drag of flow to move in the S-diffuser and this enhances the energy loss of the S-diffuser, see Fig. 13. In view of the experimental and numerical energy loss coefficients of all tested S-shaped diffuser models presented in Fig. 7, the energy loss coefficient decreases with Reynolds number because of the reduction of adverse pressure gradient generated in the S-shaped diffuser. The comparisons reveal that the flow in S-shaped diffuser model (3) exhibits greater values of the diffuser energy-loss coefficient than the other models, while model (7) exhibits the lowest value of the energy-loss coefficient. The high energy-loss coefficient of model 3 may be due its small area ratio, in which the low generated adverse pressure gradient enhances the generated counter-rotating vortices.

\section{Loss-Coefficient Correlation}

General new correlation of the S-diffuser loss coefficient for present studied cases exploring the ranges of geometrical and flow parameters can be extracted from the present experimental data. The correlation of water flow is previously discussed by Ibrahim et al. [11], while for stable (o/w) emulsion flow the correlation can be extracted from the curve fitting as given in the following equation:

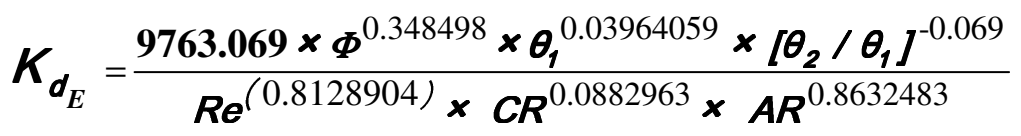

The effects of S-diffuser geometrical parameters including area ratio, curvature ratio, turn angle, and flow path on the correlated diffuser energy-loss coefficient are shown in Figs. 14 to 17, in which good comparisons between the developed correlations and the present results are noticed. 


\section{CONCLUSIONS}

Based on the measurements and computations performed in the present study on emulsion flow in S-shaped diffuser, the following conclusions can be drawn:

1) As symmetric turn angle of S-shaped diffusers increases the energy-loss coefficient.

2) As the flow path changes to asymmetric, the energy-loss coefficient strongly increases.

3) For S-shaped diffusers as the inflow Reynolds number, diffuser area ratio and the diffuser curvature ratio increase the energy-loss coefficient decreases.

4) Increasing the emulsion holdup causes an increase in the S-diffuser energy loss coefficient.

5) The unstable emulsion exhibits lower values in the energy-loss coefficients, compared with stable emulsion and each of them exhibits higher values compared with water.

6) New correlations of S-diffuser energy-loss coefficient are developed for all cases studied in the present work.

\section{REFERENCES}

[1] K. R. Manmatha and S. K. Laxman, "CFD Modeling of Pressure Drop Caused by Two-Phase Flow of Oil/Water Emulsions through Sudden Expansions", International Journal of Engineering Research and Applications (IJERA), Vol. 2, Issue 6, PP. 1047-1054, (2012).

[2] W. A. El-Askary, K. A. Ibrahim, E. Wahba, and H. A. Omara, "Emulsion (Oilin-Water) Fluid Flow in Curved Diffuser", International Journal of Fluid Mechanics Research, Vol. 40, No. 3, PP. 204-226, (2013).

[3] S. Nasr, "Hydraulic Resistances" M.Sc. Thesis, Minoufiya University, Egypt (1988).

[4] J. H. Whitelaw, and S. C. M Yu, "Flow Characteristics in an S-Shaped Diffusing Duct with Asymmetric Inlet Conditions", 11 th Australasian Fluid Mechanics Conference, University Tasmania, Hobart, Australia, PP. 139142, (14-18 December 1992).

[5] J. H. Whitelaw, and S. C. M. Yu,"Velocity Measurements in an S-Shaped Diffusing Duct", Experiments in Fluids Vol.15 (4), PP. 364-367, (1993a).

[6] J. H. Whitelaw, and S. C. M. Yu,"Turbulent Flow Characteristics in an SShaped Diffusing Duct", Flow Measurement and Instrumentation, Vol. 4 (3), PP. 171-179, (1993b).

[7] R. Pal, "Pipeline Flow of Unstable and Surfactant Stabilized Emulsions", AICHE Journal, Vol. 39, No. 11, PP. 1754-1764, (1993).

[8] C-Yi J., Hwang, and R., Pal, "Flow of Two- Phase Oil/Water Mixture through Sudden Expansions and Contractions", Chemical Engineering Journal, Vol. 68, Issues 2-3, PP. 157-163, (1997).

[9] R. Pal, and C-Yi J., Hwang, "Loss Coefficients for Flow of SurfactantStabilized Emulsions through Pipe Components", Trans. IChemE Part A, Vol. 77, PP. 685-691, (1999). 
[10] T., Balakhrisna, S., Ghosh, and , P.K., Das, "Oil-Water Flows through Sudden Contraction and Expansion in a Horizontal Pipe- Phase-Distribution and Pressure Drop", International Journal of Multiphase Flow, Vol. 36, Issue 1, PP. 13-24, (2010).

[11] K. A. Ibrahim, W. A. El-Askary, I. M. Sakr and Hamdy A. Omara., "Experimental and Numerical Studies on Water Flow through Rectangular Cross-Sectional Area S-Shaped Diffusers", Engineering Research Journal. Faculty of Engineering, Minoufiya University, Vol. 38, No. 4, PP: 309-325, (2015).

[12] ANSYS R15.0, User's Guide Contents, Fluent, Theory Guide, Turbulence and Multi-phase Models, Inc. documentation help. (2015).

Table.1. the Geometrical parameters of S-shaped diffuser models with $B=8, W=2$ and $A_{\text {inlet }}=16$ (dimensions in $\mathrm{cm}$ ).

\begin{tabular}{|c|c|c|c|c|c|c|c|c|c|}
\hline $\begin{array}{l}\text { Diffuser } \\
\text { Model }\end{array}$ & $1 \& 9$ & $2 \& 4$ & 3 & $5 \& 10$ & 6 & 7 & 8 & 11 & 12 \\
\hline$\theta_{1} / \theta_{2}$ & $45^{\circ} / 45^{\circ}$ & $45 \% 45^{\circ}$ & $45^{\circ} / 45^{\circ}$ & $45^{\circ} / 45^{\circ}$ & $45 \% 45^{\circ}$ & $60 \% 60^{\circ}$ & $90 \% 90^{\circ}$ & $60^{\circ} / 30^{\circ}$ & $30 \% 60^{\circ}$ \\
\hline$\overline{R_{\mathrm{c}}}$ & 15 & 15 & 15 & 25 & 10 & 15 & 15 & 25 & 25 \\
\hline$W_{\text {cuit }}$ & 6 & 4 & 3 & 4 & 4 & 6 & 6 & 4 & 4 \\
\hline$\overline{A_{\alpha i n}}$ & 48 & 32 & 24 & 32 & 32 & 48 & 48 & 32 & 32 \\
\hline $\mathrm{AR}$ & 3 & 2 & 1.5 & 2 & 2 & 3 & 3 & 2 & 2 \\
\hline$\overline{C R}$ & 7.5 & 7.5 & 7.5 & 12.5 & 5 & 7.5 & 7.5 & 12.5 & 12.5 \\
\hline
\end{tabular}




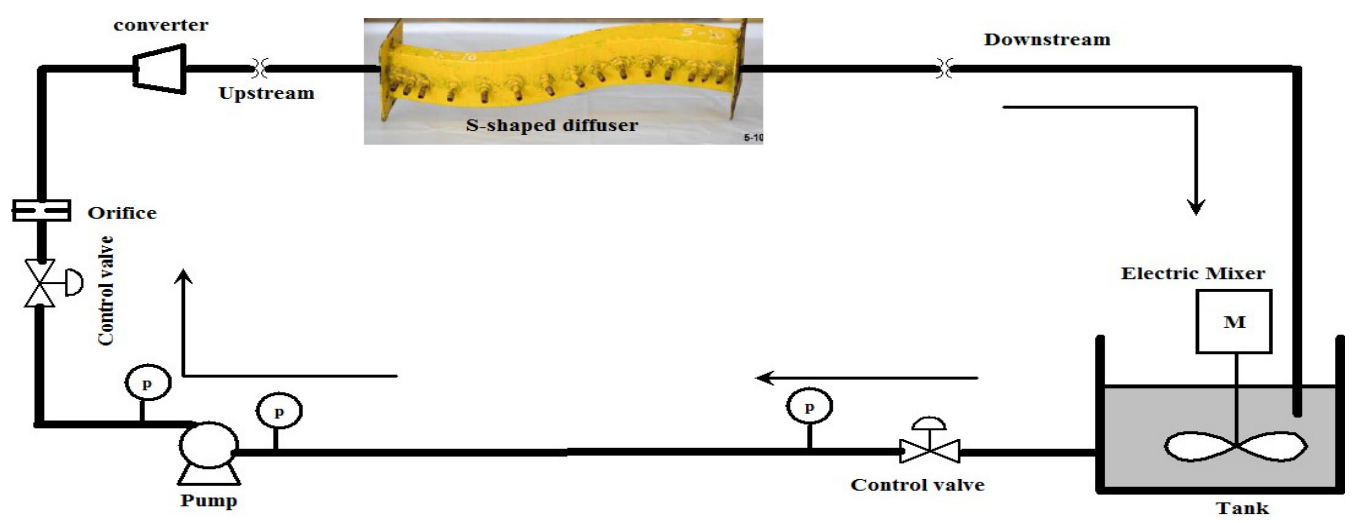

(a) Schematic diagram of the circuit (Not to scale).

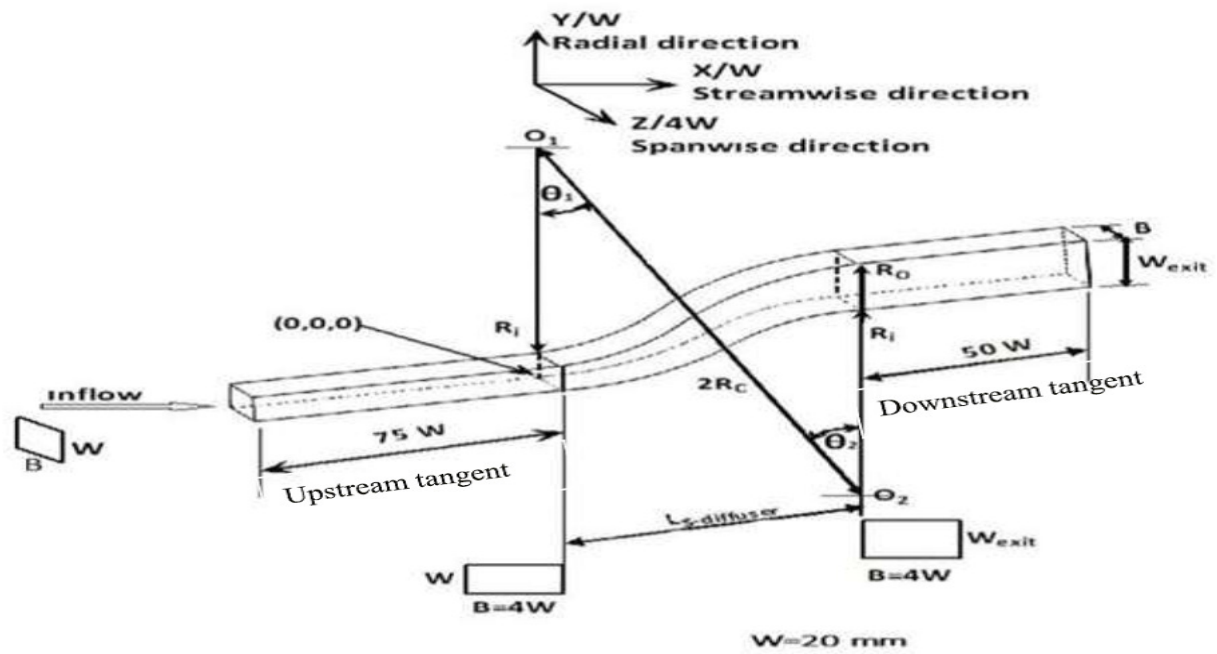

(b) Test Physical model of S-diffuser (Not to scale)

Fig. 1. Experimental setup and S-diffuser model.

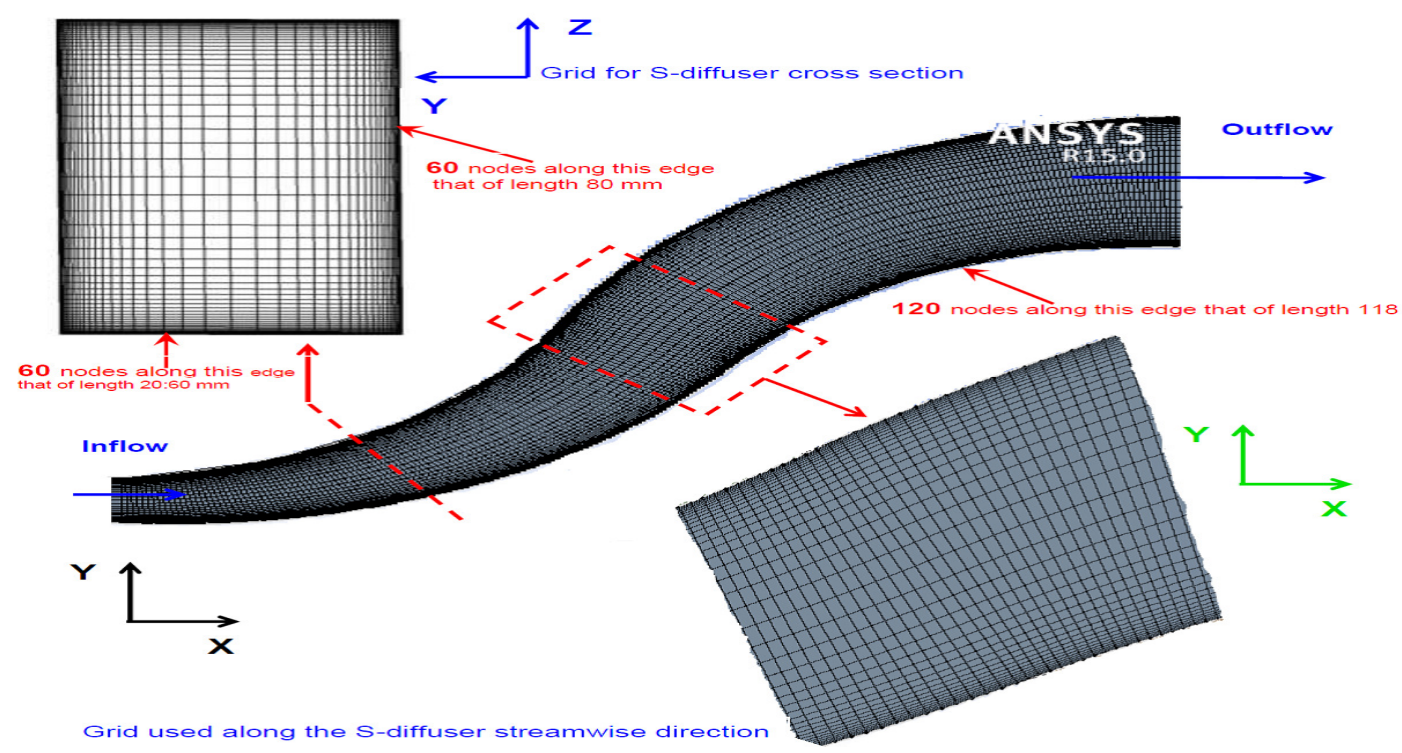

Fig.2. Grid Used for the present Computations. 


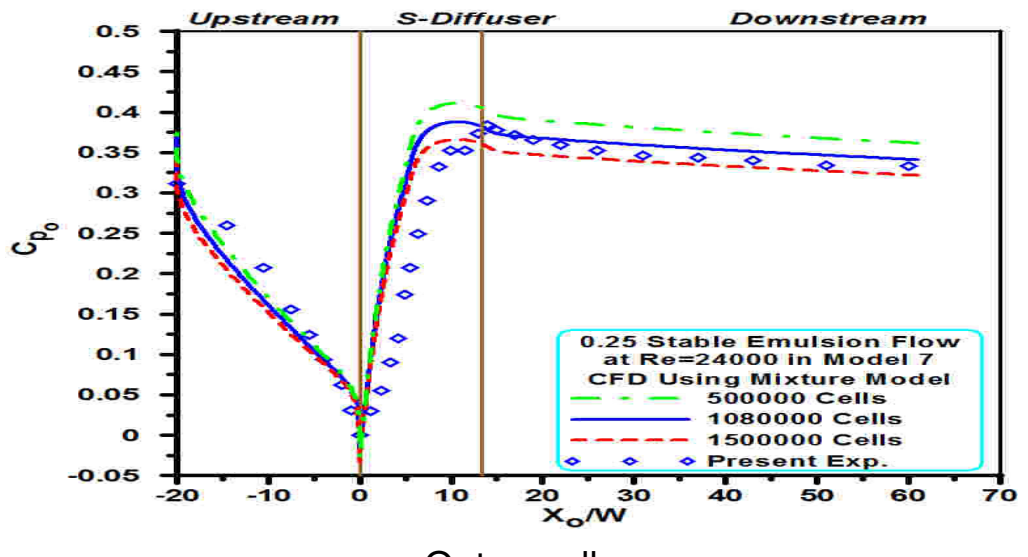

Outer-wall

Fig. 3. Computational grid and resolutions effect on the results for model 7 carrying 0.25 stable $(\mathrm{o} / \mathrm{w})$ emulsion.

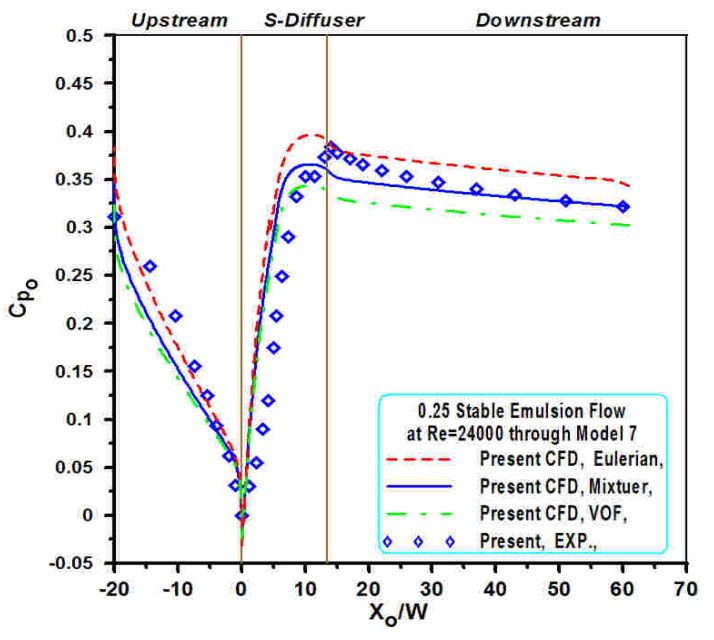

a) Outer wall

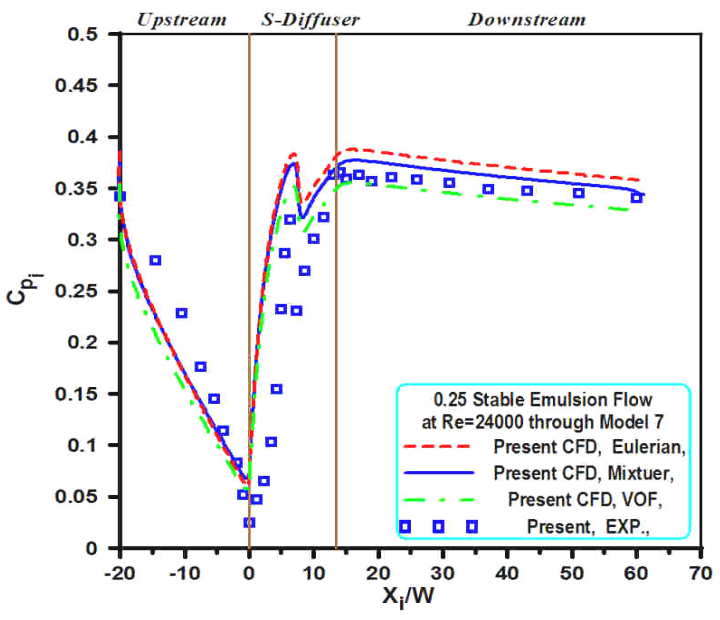

b) Inner wall

Fig. 4. Pressure coefficient distributions for model-7 carrying 0.25 stable (o/w) emulsion.

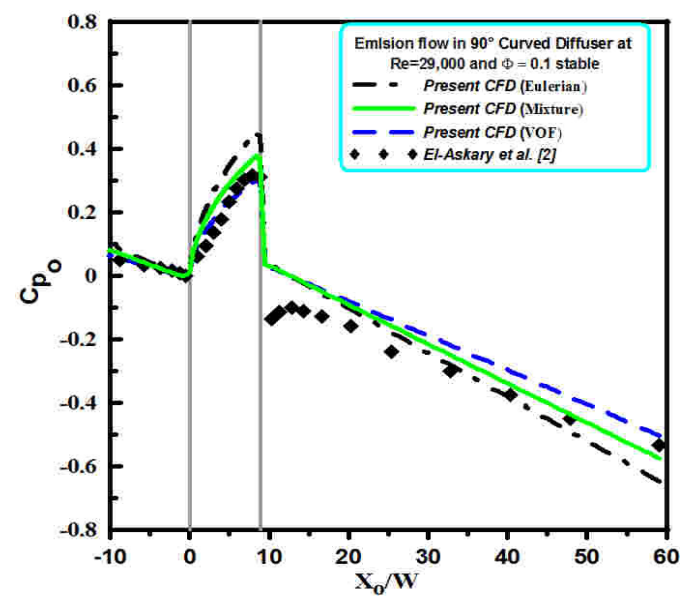

a) Outer wall

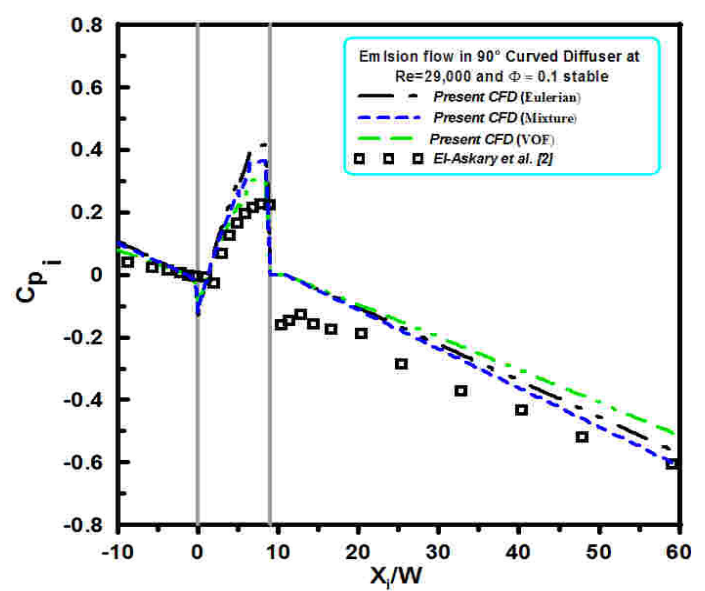

b) Inner wall

Fig.5. Pressure distributions for 0.10 stable $(\mathrm{o} / \mathrm{w})$ emulsion flowing through a $90^{\circ}$ curved diffuser at $\mathrm{Re}=29000$ [2]. 


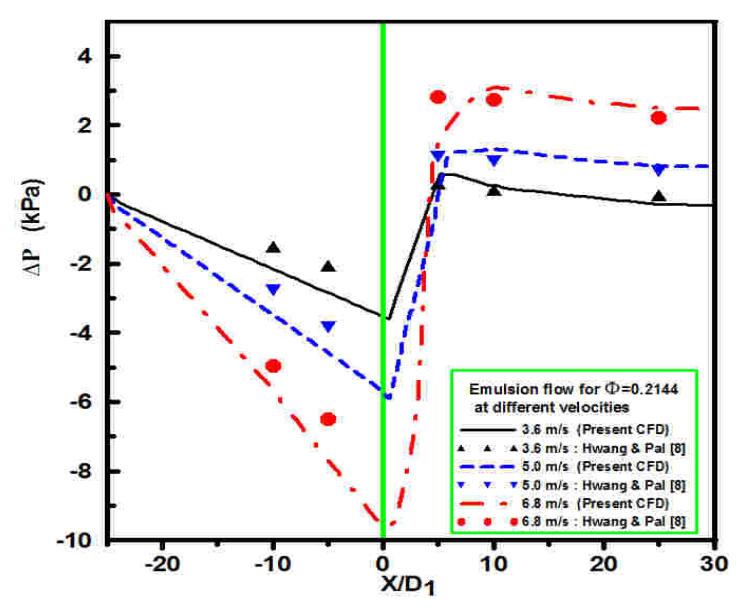

a) $\Phi=0.2144$

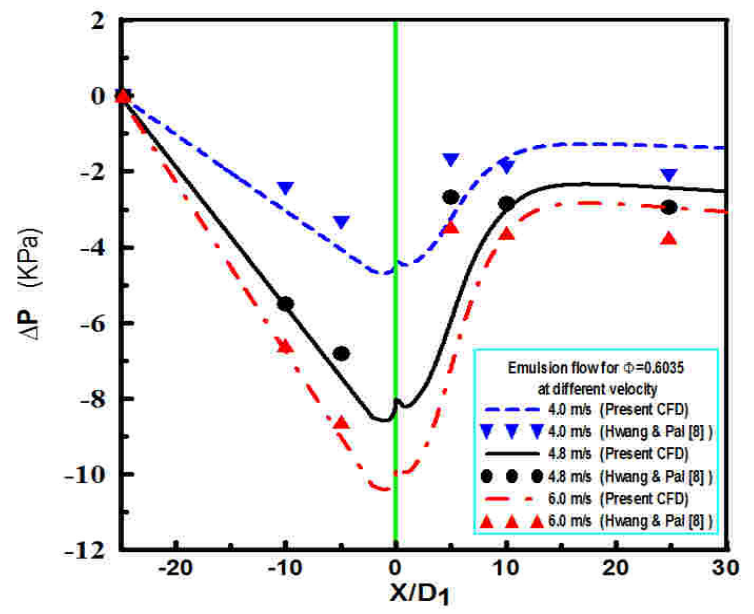

b) $\Phi=0.6035$

Fig.6. The pressure drop of unstable (o/w) flowing through a sudden expansion at different holdup values and velocities, (measurements of [8]).

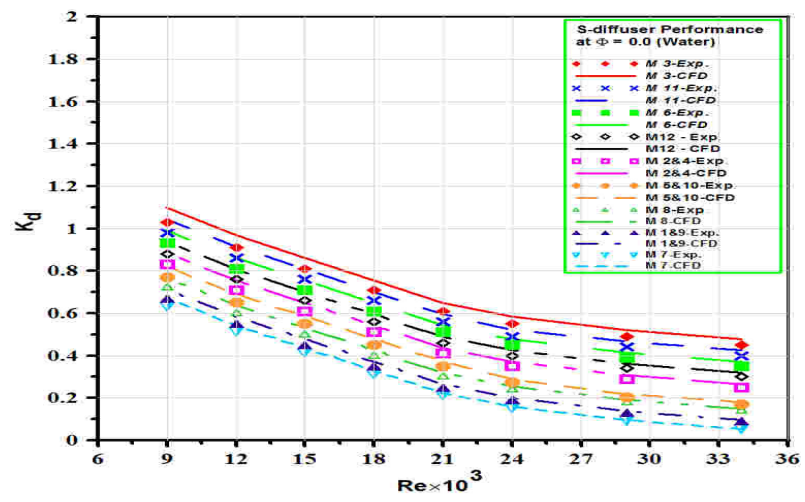

a) water

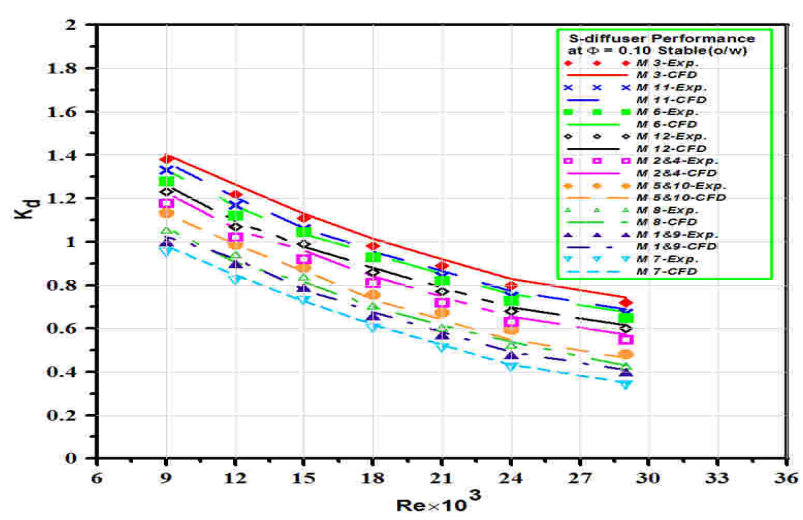

c) $\Phi=0.1$ (stable)

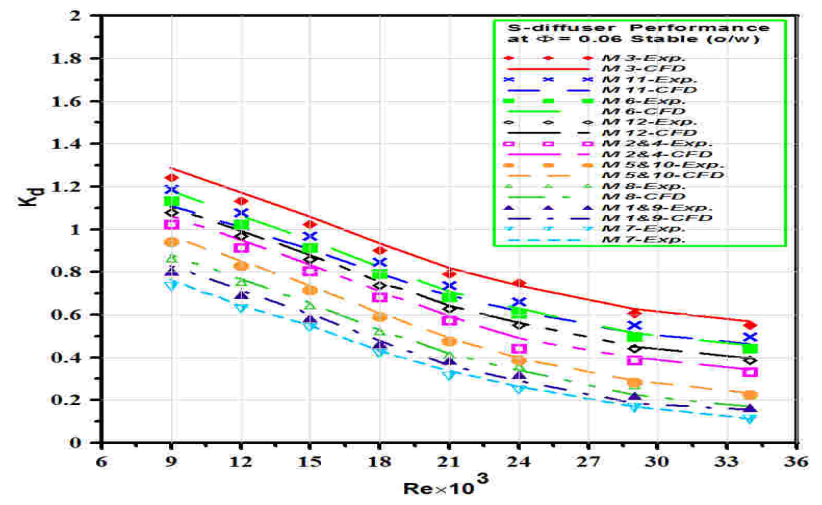

b) $\Phi=0.06$ (stable)

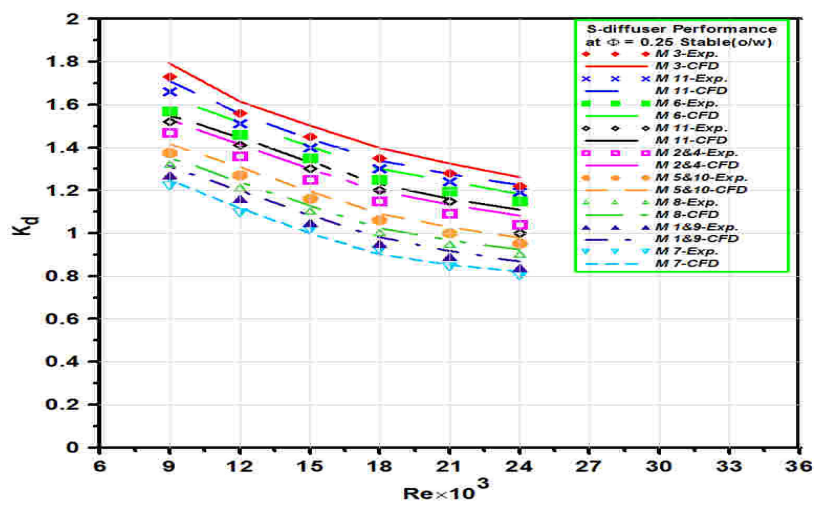

d) $\Phi=0.25$ (stable)

Fig. 7. Effect of inflow Reynolds number on the diffuser energy-loss coefficient for all models carrying water and stable (o/w) emulsion. 


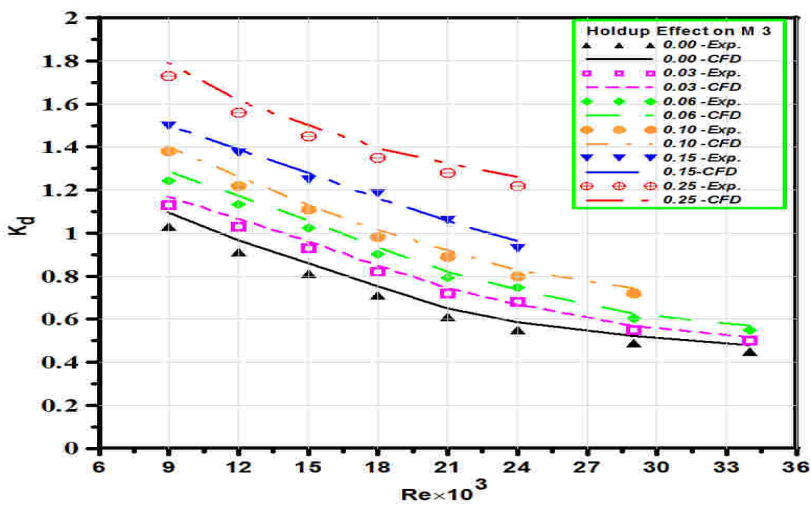

a) $\mathrm{M} 3$

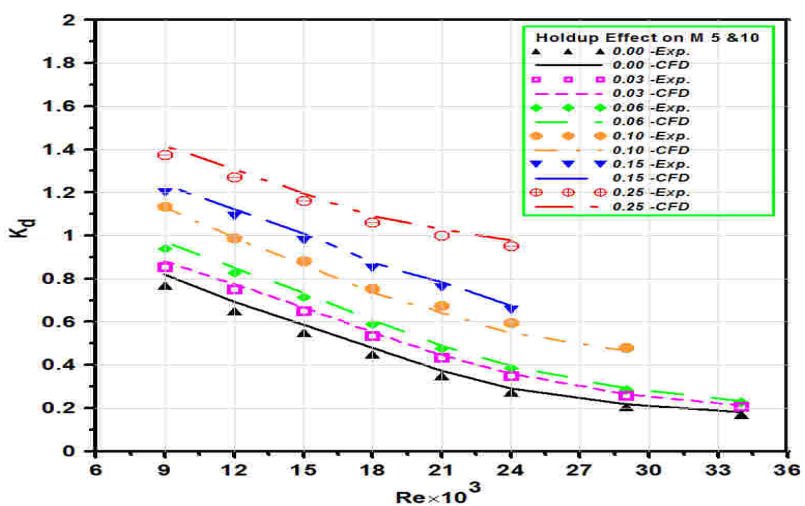

c) $M 5 \& 10$

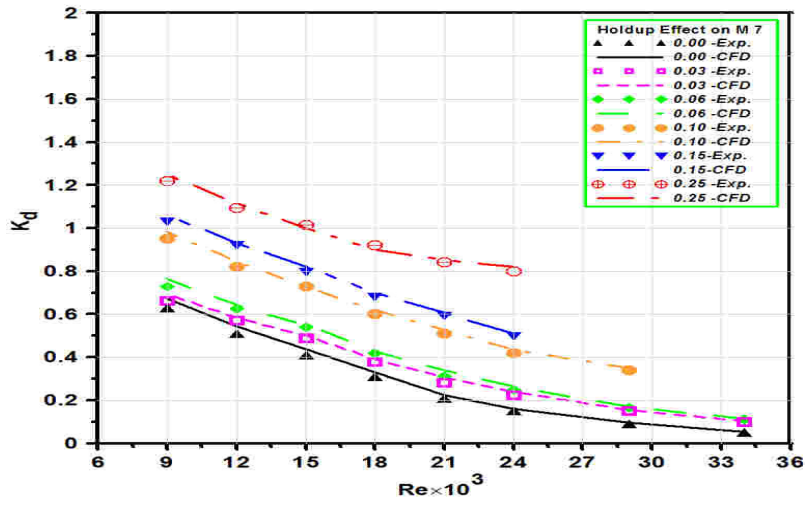

b) $\mathrm{M} 7$

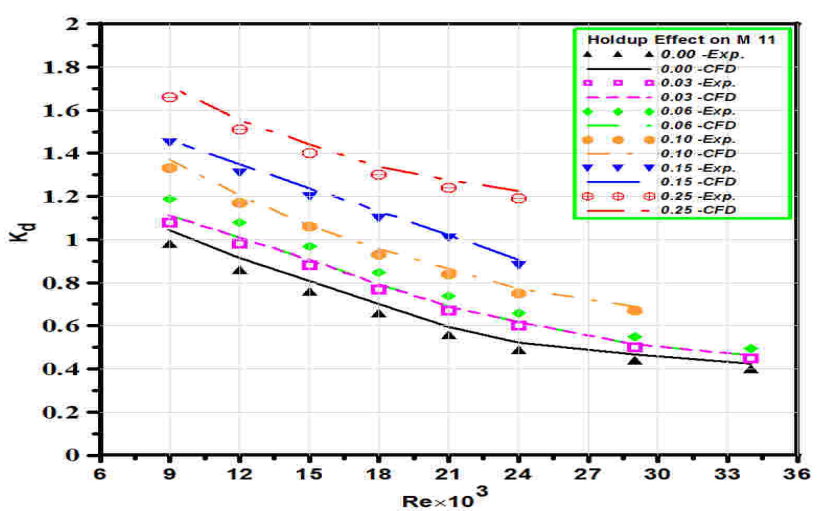

d) $M 11$

Fig. 8. Effect of emulsion holdup on the diffuser energy-loss coefficient for models $(3,5 \& 10,7,11)$ carrying water and stable $(\mathrm{o} / \mathrm{w})$ emulsion.

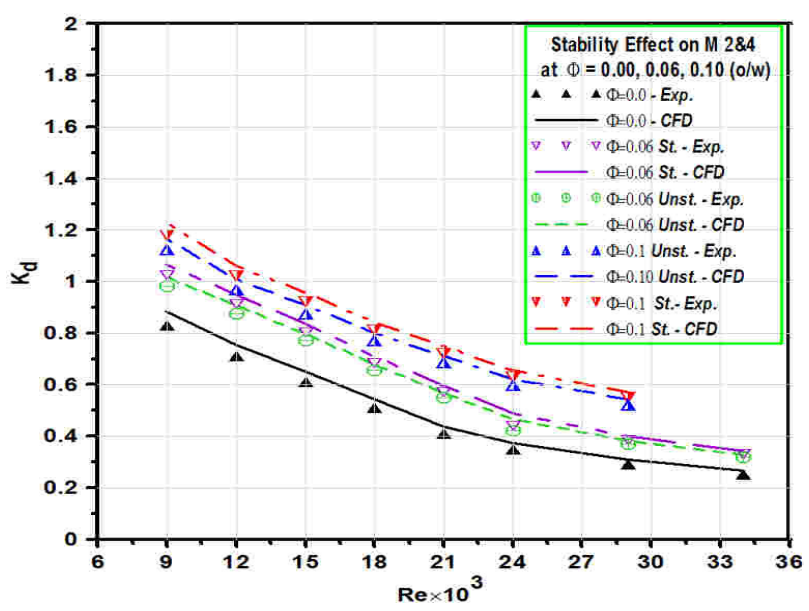

a) M 2\&4

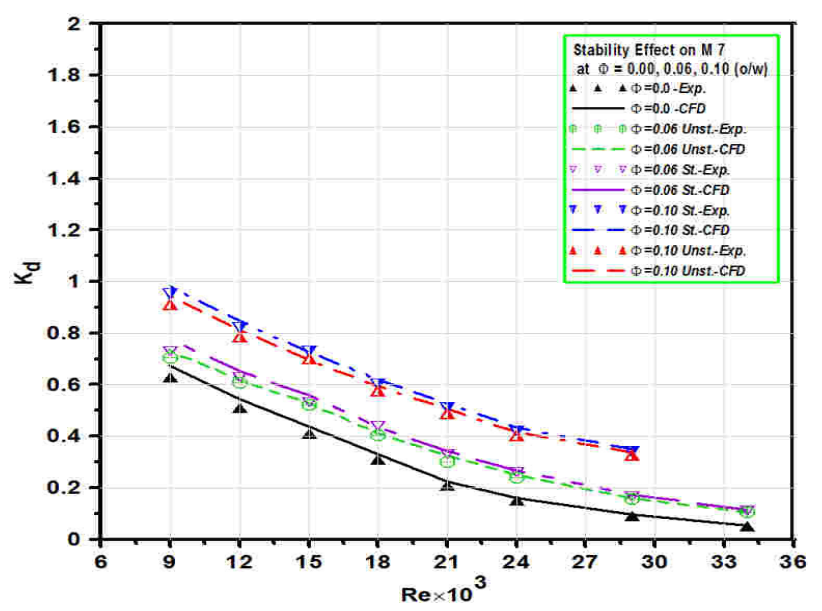

b) $M 7$ 


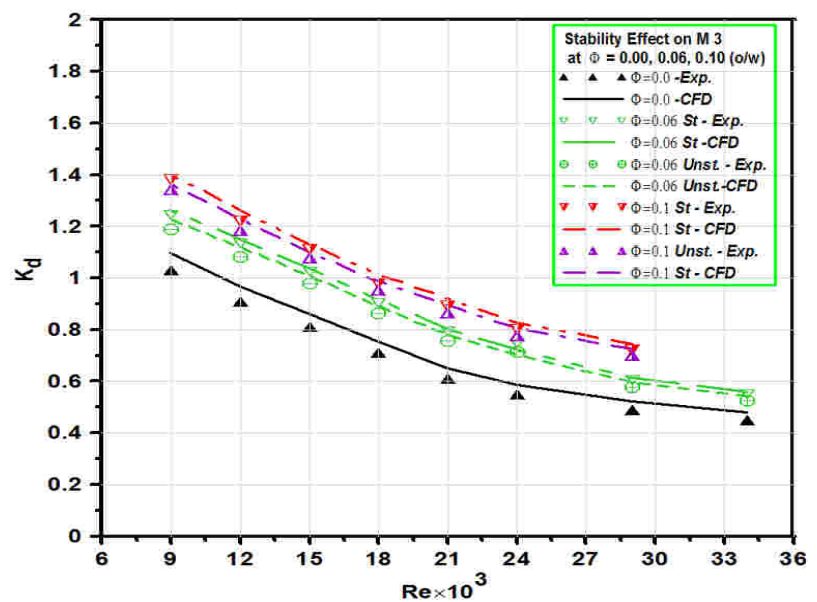

c) $\mathrm{M} 3$

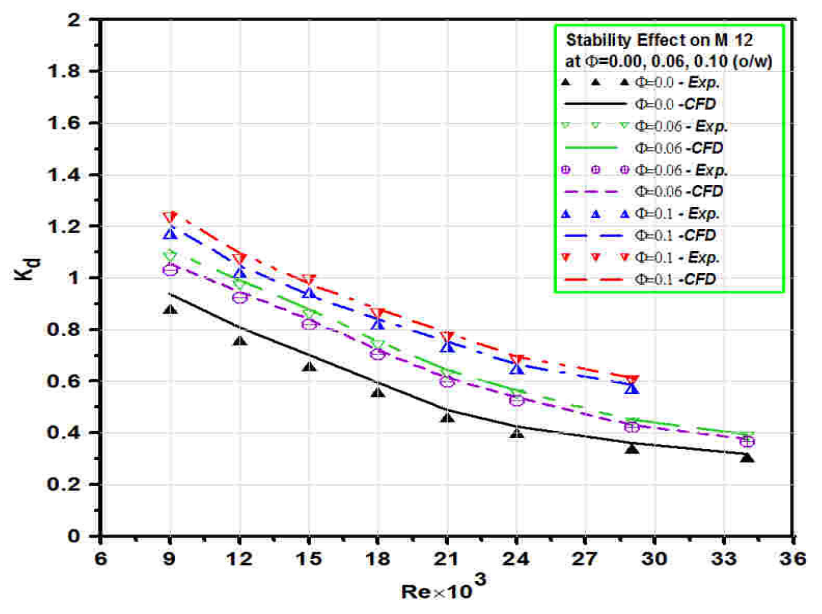

d) M 12

Fig. 9. Effect of emulsion stability on the diffuser energy-loss coefficient for models $(2 \& 4,3,7,12)$ carrying water and stable/unstable (o/w) emulsions.

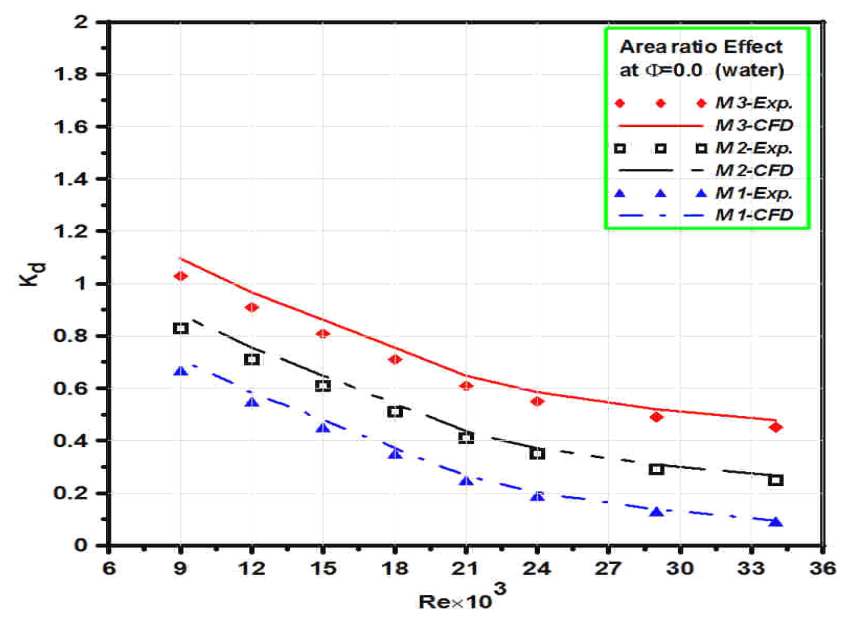

a) water

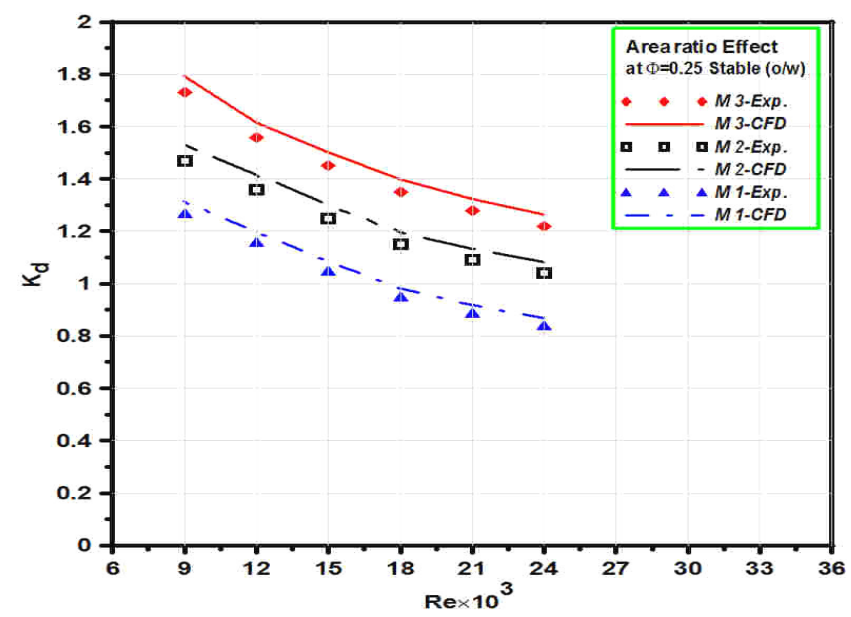

b) 0.25 (Stable)

Fig. 10. Effect of diffuser area ratio on the diffuser energy-loss coefficient in case of water and $(\mathrm{o} / \mathrm{w})$ emulsion flows.

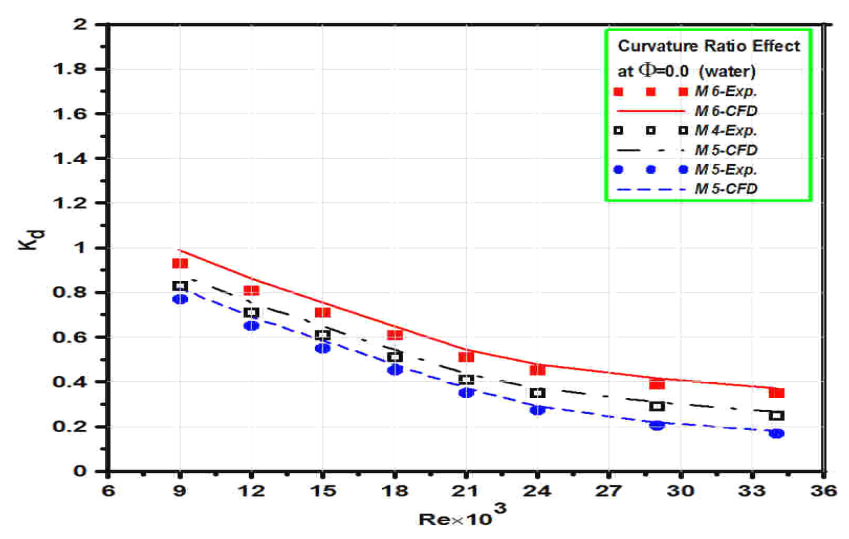

a ) water

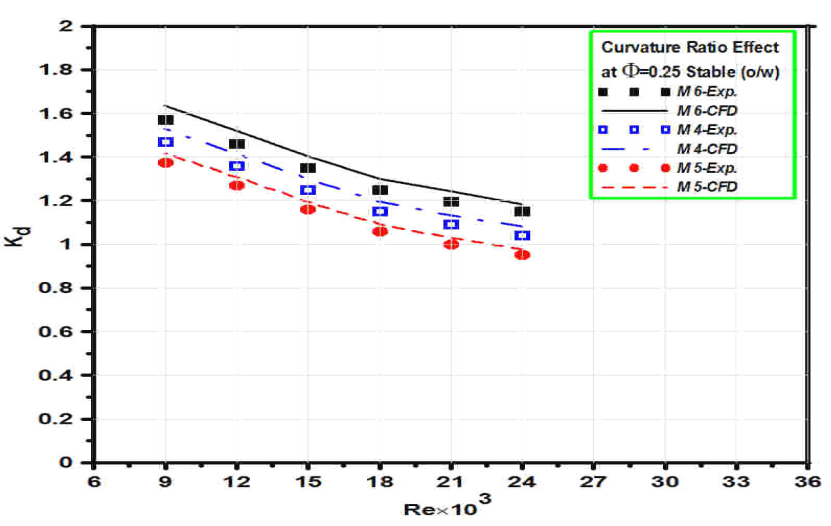

b ) 0.25 (Stable)

Fig. 11. Effect of diffuser curvature ratio on the diffuser energy-loss coefficient in case of water and emulsion flows. 


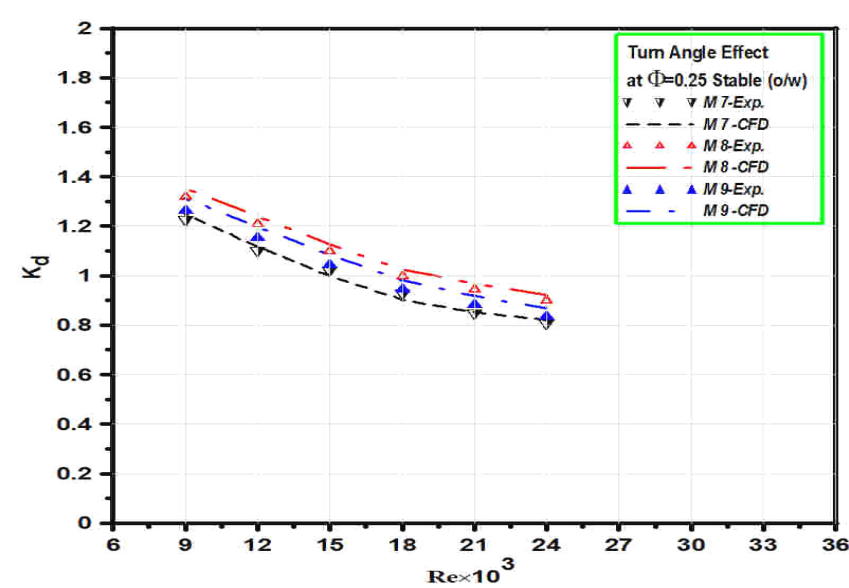

Fig. 12. Effect of diffuser turn angle on the diffuser energy-loss coefficient in case of 0.25 (stable) flows.

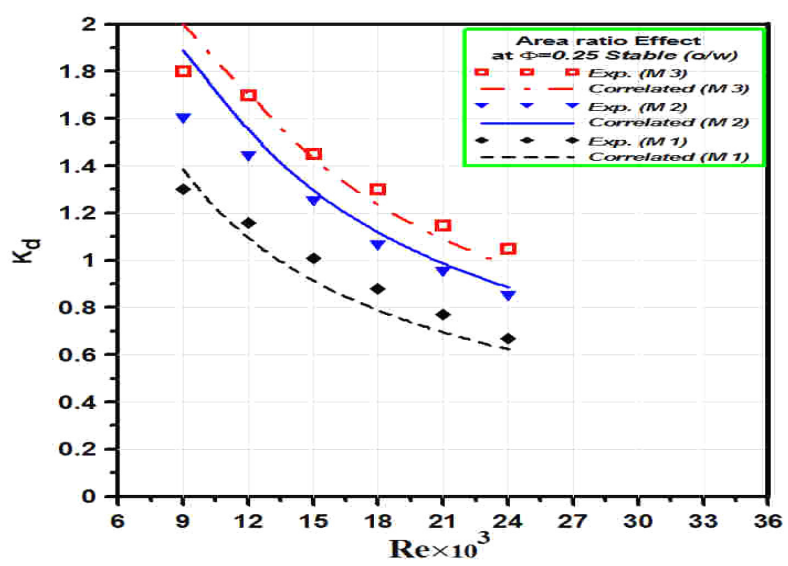

Fig. 14. Curve fitting of curvature ratio effect on the energy-loss coefficient in case of 0.25 (stable) flows.

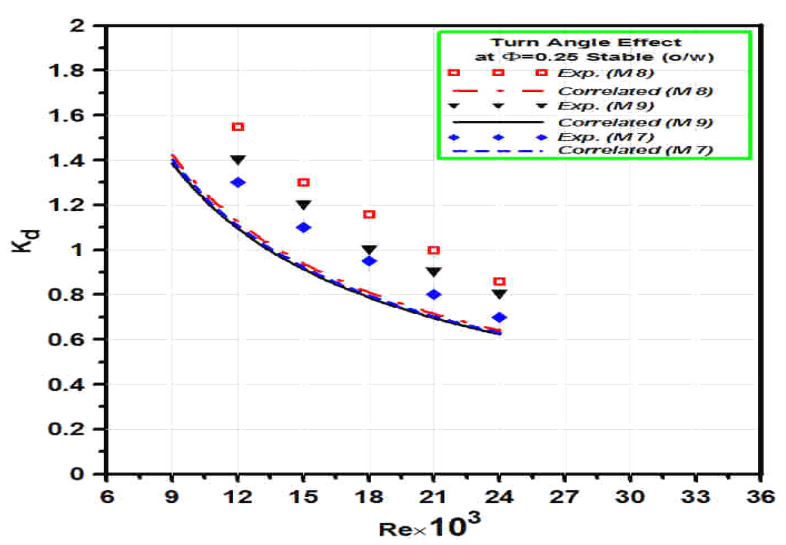

Fig. 16. Curve fitting of Turn angle ratio effect on the energy-loss coefficient in case of 0.25 (stable) flows.

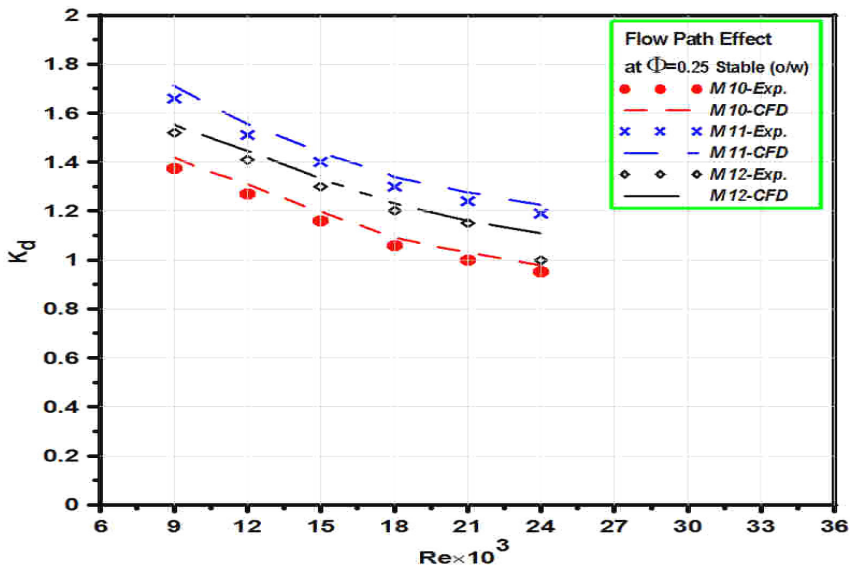

Fig. 13. Effect of diffuser flow path on the diffuser energy-loss coefficient in case of 0.25 (stable) flows.

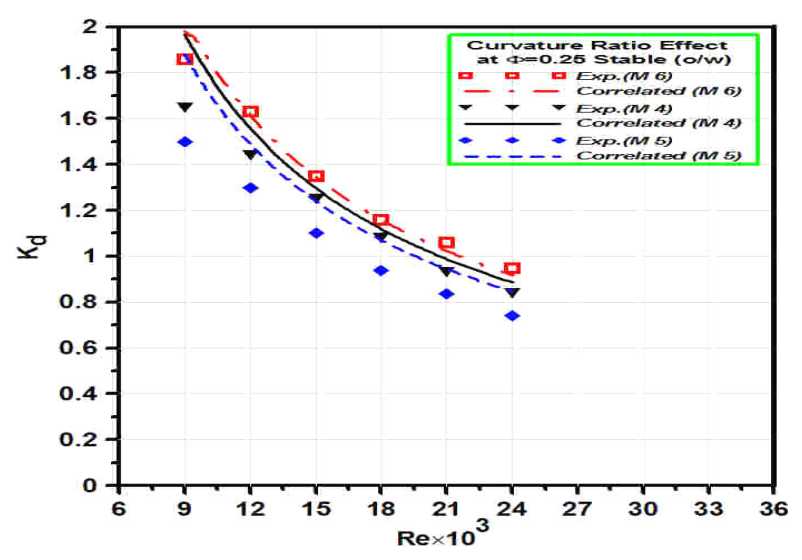

Fig. 15. Curve fitting of curvature ratio effect on the energy-loss coefficient in case of 0.25 (stable) flows.

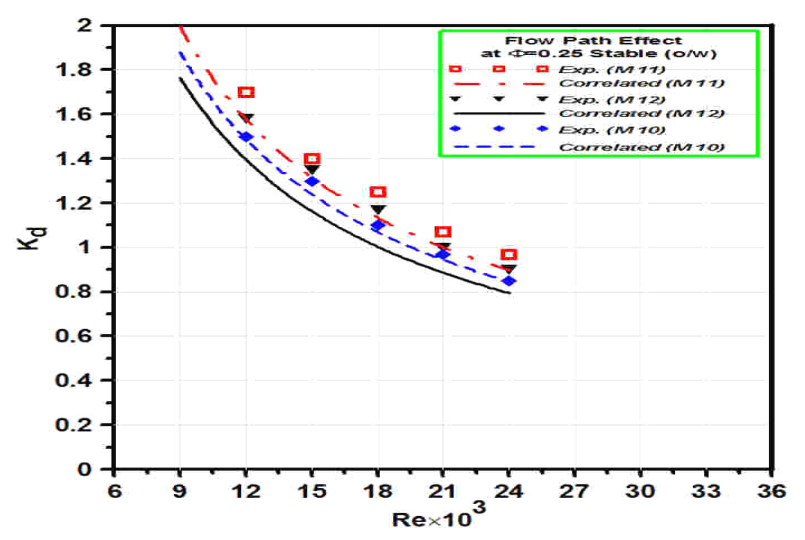

Fig. 17. Curve fitting of Flow Path ratio effect on the energy-loss coefficient in case of 0.25 (stable) flows. 